\title{
Letter-to-the-Editor
}

\section{Assessing the Present and Future Roles of Infectious Diseases Specialists in Treating Infections}

I decided to write this letter hoping to stimulate a debate among infectious diseases specialists about an important every day issue - what kind of patient has been left to be cared for infectious diseases specialists? This question, I believe, has been coming up in every Brazilian general Hospital where we work and make our livings.

I'll never forget the remarkably outspoken and sincere commentary of one surgeon in an ICU in a hospital in my city, about a patient I had at that time; "Do you infectious diseases specialists treat pneumonia? Sorry, I didn't know, and by the way, I already asked for a second opinion from a pneumologist!" This event is not an isolated one, unfortunately, with clear results in the infectious diseases specialist's income at the end of the month.

In Brazil, almost all infected patients, regardless of the kind of infection they have, are referred to some "anatomic" medical specialist for treatment.

If a patient has pneumonia or even just a fever with a cough, a pneumologist will be called; if he has diarrhea, whether or not there is fever and sepsis, a gastroenterologist will be called, and it's easy to figure out, of course, all icteric patients follow the same path.

Herpes zoster? Cutaneous leishmaniasis? Ok let's call a dermatologist. Meningitis? No doubt, a neurologist. The list is simply endless. This is our reality; at least the one I see.

The progressive decline of internal medicine as a medical specialty [1-3] has certainly left a vacuum immediately replaced by many anatomic (or horizontal) clinical subspecialties. Maybe the problem is that the specialty of infectology arrived too late in the history of medical practice. Maybe some specific marketing has been lacking. Maybe all vertical medical specialties will just fade away in the future.
This is just one person's opinion, but something has to be done, not only because the economic result of this ongoing process means low incomes, but also because infectious diseases specialists have shown more ability to deal with sick patients because they see human illness as a whole rather than as a single organ disorder; because they refine their diagnosis, tracking down the etiologic agents of the infections; and because they have two respected societies with high quality journals . They can also provide more rational use of antibiotics [4, 6]. Infectious diseases specialists also have a special history, where names like Carlos Chagas, Rocha Lima, Almeida, and their successors have helped to construct the most respectable parts of Brazilian medical knowledgesomething many very well established and wealthy anatomic specialties don't have here in Brazil.

As the economic rewards decrease, the discipline will appear progressively less attractive to students, residents, and practitioners. If we stop seeing patients with different types of infections, we will lose the important skill of "observation", considered a long time ago by William Osler [5] to be the most important tool for medical teaching. I don't think infectious diseases specialists have the right to monopolize all infected patients, but the opposite is just not acceptable. After all, according to Brazilian law, every doctor has the right to treat everything he feels capable of. If a disease has not been resolved satisfatorily, doctors (even infectious diseases specialists), patients, and their relatives, will be tempted to ask for "specialists" to treat "anatomic" infections. Our skill at identifying potential etiologic agents, and of initiating proper antimicrobial therapy will be missing, as will the clinical experience for ourselves. 
Jones, in a previous editorial [6], emphasized a possible and potential leadership role for infectious diseases specialists in hospitals. My view is that much more is needed, not necessarily for the senior specialists but especially for the newcomers to the specialty. We should start by considering ourselves capable of simple things, such as treating patients suffering from infectious diseases regardless of the target organ.

Paulo Sérgio Gonçalves da Costa Barbacena Medical School, Barbacena, $M G$, Monte Sinai Hospital, Juiz de Fora, MG, Brazil

\section{References}

1. Braunwald E. Subspecialists and internal medicine: a perspective Ann Intern Med 1991;114(1):76-8.

2. Reitermeier R. The leadership crisis in internal medicine: what can be done? Ann Intern Med 1991;114(1):69-75.

3. Nolan J.P., Inui T.S. Tinkering the real reform? The choice is ours. Ann Intern Med 1992;116(12):1042-5.

4. Behar P., Wagner M.B., Freitas I., et al. Assessing the antimicrobial prescription request process in a teaching hospital in Brazil: regulations and training. Braz J Infec Dis 2000;4(2):76-85.

5. Belkin B.M., Neelon F.A. The art of observation: William Osler and the method of Zadig. Ann Intern Med 1992;116(10):863-6.

6. Jones T.C. New roles for the infectious diseases physician in the hospital: leadership, organization, and teaching by example. Braz J Infect Dis 1998;2(4):212-3. 